\title{
CONSIDERING THE ELDERLY'S NEEDS IN DEVELOPING NURSING HOME DESIGN
}

\author{
MANURUNG, Parmonangan \\ Department of Architecture, Faculty of Architecture and Design, Universitas Kristen Duta Wacana \\ Jl. Dr. Wahidin Sudirohusodo No.5-25, Yogyakarta - INFONESIA \\ Email: monang@staff.ukdw.ac.id
}

\begin{abstract}
Statistics show that the elderly people population has increased every year, which makes the role of the nursing home, becomes very important. However, most nursing home has not been able to meet the needs of the elderly who have different needs due to changes in their physical and psychological abilities. This research was conducted at two nursing homes and aims to find the design changes and design development that occur to accommodate the needs of the elderly. A descriptive qualitative was employed, and in-depth interviews, field observation, literature reviews, and field measurements were conducted for collecting data. The data was coded and analysed using descriptive qualitative content approach. The results showed some changes were developed to meet the needs of the elderly as they experience changes in physical and psychological condition. The original design did not meet the need of elderly residents, therefore some development had been made. Design developments have already met and supported the activities of the elderly residents.
\end{abstract}

Keywords: Elderly people; nursing home; physical limitation; design development; user-centered.

\section{INTRODUCTION}

The population of the elderly people in developing countries has increased (Calefato et al., 2014; Liu \& Speed, 2014), This trend also occurred in Indonesia as shown by Statistics Indonesia (2013) that in 2010, the Indonesian population aged over 60 years, amounting to 18 million $(7.56 \%)$, while in 2016 amounted to 22.6 million (8.74\%), and in 2035 is expected to increase to 48.2 million (15.77\%). This increase affects nursing home (elderly care institution) to accommodate the needs of the elderly, especially those who do not have a home to stay or not cared for by their family. Developing countries have long established a nursing home to accommodate the elderly (Liu et al., 2015).

The majority of nursing home does not meet the needs of the elderly both in quality and quantity (Liu et al., 2015). On the other hand, the elderly have different needs to access and use the facilities in the building because they have physical and cognitive abilities (Calefato et al., 2014), these different requirements are often not accommodated even in a nursing homes which were designed and intended as the residence of the elderly people both temporarily or permanently. Designs of nursing home often use the same standards as other building functions, regardless of the different needs of the elderly. As mentioned Nurdiah \& Hariyanto (2015), most of architectural theories about space and place are built based on western views. This understanding often makes architects are not oriented to the needs of users in designing a public facility, including nursing home.

This research was conducted at two nursing homes in Yogyakarta that have a different background in function, namely Nursing Home of Perandan Padudan which was originally an orphanage and Nursing Home of Santa Monika, which was originally designed as an nursing home. The study aims to find changes and design developments of both nursing homes, particularly in its interior space, which is done to meet the needs of the elderly people lived in these nursing homes. Through the results of this study are expected to include consideration of the design used in the design of nursing homes so that they can meet the needs of the elderly as a user.

\section{METHODOLOGY}

\section{Study Design}

In order to achieve the research objective, a descriptive qualitative design was chosen to explore the development of nursing home design which accommodated the needs of elderly residents. In-depth interviews were conducted with managers of the nursing home to get information about nursing home design development, and to find out how the design development process had been implemented. In addition, interviews were also conducted with elderly nursing home residents in order to determine whether the development of design has already been 
able to accommodate their needs and activities. To enrich data, field observation and literature review were also employed.

\section{Data Collection and Instruments}

This research was conducted through the field observation to obtain the existing condition of the interior and the design development which had been done into these nursing homes. Measurements were adopted using laser-distance measurer to obtain the dimensions of room, handrail, ramp, door, and other interior elements. The measurement data were collected and used to produce drawings plan and other two dimensional drawings needed. Meanwhile, visual condition data were collected using a camera in order to acquire the existing conditions and the atmosphere inside building. In-depth interviews with manager of nursing homes and elderly people live in these buildings, were conducted to obtain the data about design changes that have been developed to meet the needs of the elderly. Semi-structured questionnaires both for nursing home manager and elderly residents were designed in Indonesian and Javanese language in order to communicate with some elderly people who could not speak in Indonesian language. Some students who are able to speak in Javanese language were chosen to interview the elderly in this language. A cellular phone was used to record the conversation between reviewer with either nursing home manager and elderly resident with their permission. Literature reviews were conducted to obtain data about the psychological and physical of elderly people.

\section{Data Analysis}

All of collected data were coded and analysed using a descriptive qualitative approach. The recorded interviews were transcribed then the transcript was read carefully to get information needed for analysis phase. The data obtained from nursing home manager used to identify the changes or developed design that occur in these nursing homes, while the data of the elderly residents used to assess whether the design changes have already met their needs. The data were developed into matrix and drawings to facilitate the analysis process. Then, the interviews data were analysed with observational data and theory reviews to draw a conclusion

\section{Case Study}

In order to enrich the data, two nursing homes having different background in function was chosen, one nursing home had been designed as a nursing home originally, and another as a non-nursing home. Therefore, the study was conducted at two women nursing homes located in Yogyakarta, Nursing Home of Perandan Padudan and Nursing Home of Santa Monika, which have different design backgrounds. Nursing Home of Perandan Padudan originally was designed as an orphanage, while Nursing Home of Santa Monika had been designed as a nursing home originally and accommodated elderly activities. Both of these nursing homes were selected as a research case study in order to enrich the information about the design development that occurred in a nursing home, either in buildings that switching function as a nursing home, or on the building which was designed as another function.

\section{LITERATURE REVIEW}

\section{Physical and Psychology of Elderly}

Elderly people are similar with children, both categorized as a vulnerable generations because of their physical condition (Calefato et al., 2014). Ozcan et al. (2005) mentioned that one the main health problem of elderly people is falls (balance, functional mobility, muscle strength, fear or falling) which will be affecting their quality of life. Health of the elderly is very important and has been linked to their psychological condition (Liu, Beaver, \& Speed, 2014). Meanwhile, the psychology of aging is about the function of physical, cognitive and emotion of elderly people (Belsky, 1999). Psychological factors can affect the comfort of the elderly living in the nursing home, and in turn would affect their health for the elderly are vulnerable generation due to physical limitations (Calefato et al., 2014). On the other hand, a dietary habit has a big impact for the elderly and one of them is loneliness (Benitez, J., Perejon, N., Arriaza, M. \& Bellanco, P. (2012). Meanwhile, Dzierzewski, et al. (2015) discovered that sleep duration will affect relationship between inflammatory markers and global cognitive functioning.

\section{Nursing Home}

Nursing home was established to accommodate and care for the elderly as well as providing protection for the poor and has long been established in developing countries (Chabeli, 2003; Liu et al., 2015). More Liu et al. (2015) said that the majority of nursing homes do not meet the needs of users, both in quantity and quality. 
Most of the elderly are generally prefer to stay at home instead of in nursing home (Liu et al., 2015; Ravishankar, Burleson \& Mahoney, 2015), therefore it is important to create a comfortable atmosphere for the elderly. Calefato et al. (2014) mentioned the importance of design education that focus on vulnerable generation like elderly people, so it can produce designs with user-centered. Therefore, the nursing home must be designed to be accessible and well used by the elderly, because of its accessibility and design concerns everyone, and the design should have their benefits and usefulness (Nussbaumer, 2011; Steinfeld \& Maisel, 2012). According Tanuwidjaya (2004), the combination of the Seven Principles of Universal Design and Three Principles of Inclusive Design produced five principles of inclusive design are: user-centered; equitable use but reasonable; simple and intuitive use; low physical effort; and prohibition of usage error." These principles can be applied in the design of nursing homes so that it can meet the needs of the elderly as well as physical and psychological condition to accommodate the elderly.

\section{RESULTS and DISCUSSION}

\section{Nursing Home of Peradan Padudan}

Perandan Padudan is a nursing home, managed and financed by the Javanese Christian Church (GKJ) Gondokusuman, and is located in the city of Yogyakarta, Province of Special Region of Yogyakarta. This nursing home was built in 1943 (Figure 1) to serve as an orphanage, and had been changed as a nursing home to accommodate the needs of the elderly residents. Perandan Padudan has a capacity of fifteen elderly people and is currently occupied by ten women elderly. Interview with the manager and field observation showed that some design changes had been developed in order to accommodate the elderly's needs (Table 1) including adding a handrail from every bedroom to the bathroom; a special room for the elderly who need special care; changes in the design of the door into the door that could be opened both on the bottom and on the top; adding ramp; and replacement flooring material. After obtaining data about design development, research team then conducted interviews with the elderly to obtain information on whether the development of the design already meets their needs. Interviews with most of the elderly showed their responses to the development of the design as shown in Table 1.
Table 1. Design development of Nursing Home of Perandan Padudan

\begin{tabular}{|c|c|c|}
\hline $\begin{array}{c}\text { Design } \\
\text { development }\end{array}$ & Development goal & Elderly respond \\
\hline handrail & $\begin{array}{l}\text { helping elderly moving } \\
\text { from one room to another }\end{array}$ & very helpful \\
\hline special room & $\begin{array}{l}\text { provided for helping } \\
\text { elderly needed special care }\end{array}$ & very helpful \\
\hline door design & $\begin{array}{l}\text { Re-designed to help } \\
\text { caregivers giving first aid if } \\
\text { an accident happened } \\
\text { inside bathroom }\end{array}$ & very helpful \\
\hline ramp & $\begin{array}{l}\text { helping elderly accessing } \\
\text { different floor level }\end{array}$ & too steep \\
\hline floor material & changed for elderly safety & helpful \\
\hline lighting & $\begin{array}{l}\text { helping elderly doing their } \\
\text { activities }\end{array}$ & $\operatorname{dim}$ \\
\hline
\end{tabular}

Extra handrail is installed to help the elderly move from one room to the bathroom and other rooms (Figure 2). Besides on the corridors, some handrails were also provided in all bedrooms, in the bathroom, and the toilet. While the design of the door to be replaced because some of the elderly had an accident in the bathroom unattended caregiver. With the doors that can be opened in two parts (Figure 3), the caregiver can immediately know if the elderly had an accident in the bathroom. On the other hand, the addition of ramp and replacement of flooring materials with a rougher texture, intended that the elderly have ability to access all rooms safely.

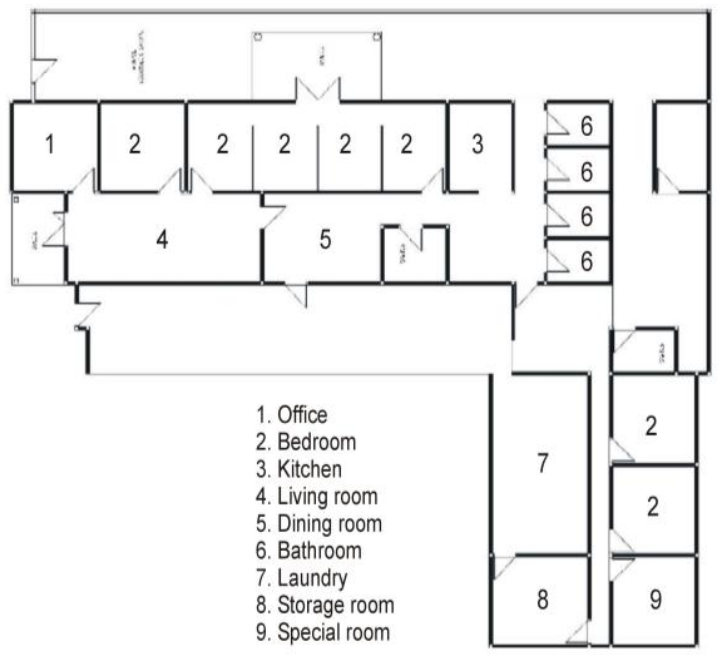

Figure 1. Floor Plan of Nursing Home of Perandan Padudan 

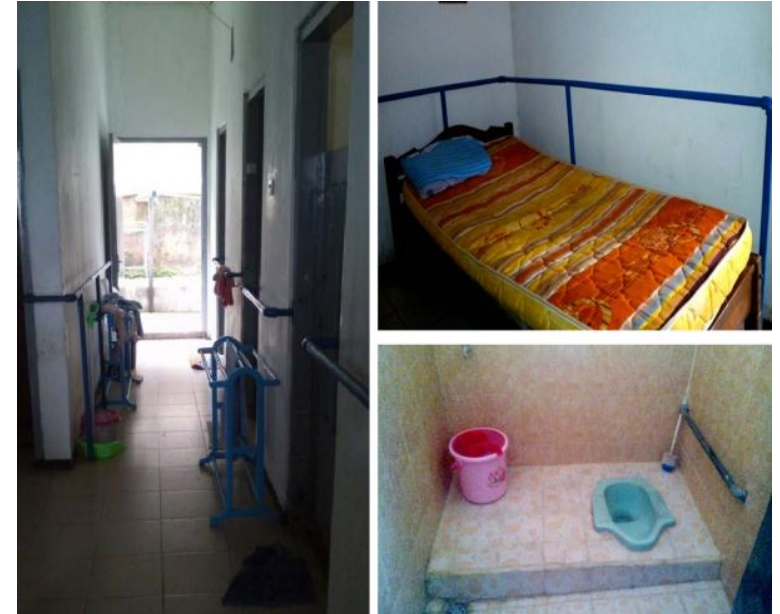

Figure 2. Handrail had been installed to help elderly to access al room.
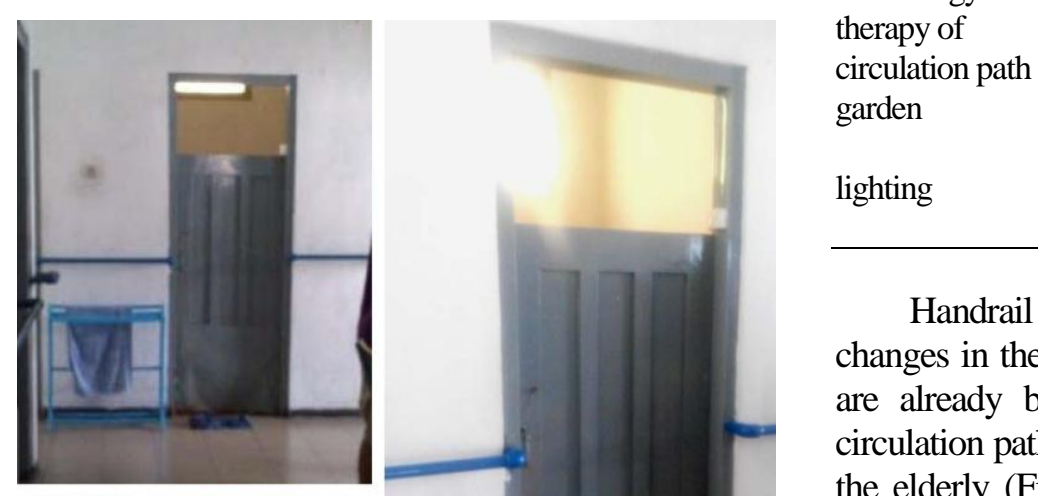

garden

lighting

\begin{tabular}{llc}
\multicolumn{1}{c}{$\begin{array}{c}\text { Design } \\
\text { development }\end{array}$} & \multicolumn{1}{c}{ Development goal } & \multicolumn{1}{c}{$\begin{array}{c}\text { Elderly } \\
\text { respond }\end{array}$} \\
\hline handrail height & $\begin{array}{l}\text { lowered to } \\
\text { accommodate physical } \\
\text { changes of elderly } \\
\text { provided for reflexology } \\
\text { therapy }\end{array}$ & as needed \\
$\begin{array}{l}\text { reflexology- } \\
\text { therapy of } \\
\text { circulation path } \\
\text { garden }\end{array}$ & $\begin{array}{l}\text { provided for elderly } \\
\text { activities } \\
\text { helping elderly doing } \\
\text { their activities }\end{array}$ & very helpful \\
lighting & & good \\
\hline
\end{tabular}

Handrail heights lowered to accommodate changes in the physical condition of the elderly who are already bent (Figure 5). The addition of the circulation path as reflexology therapy is provided for the elderly (Figure 6). In addition, to accommodate the activities of the elderly provided garden which could be planted various productive plants (Figure 7).

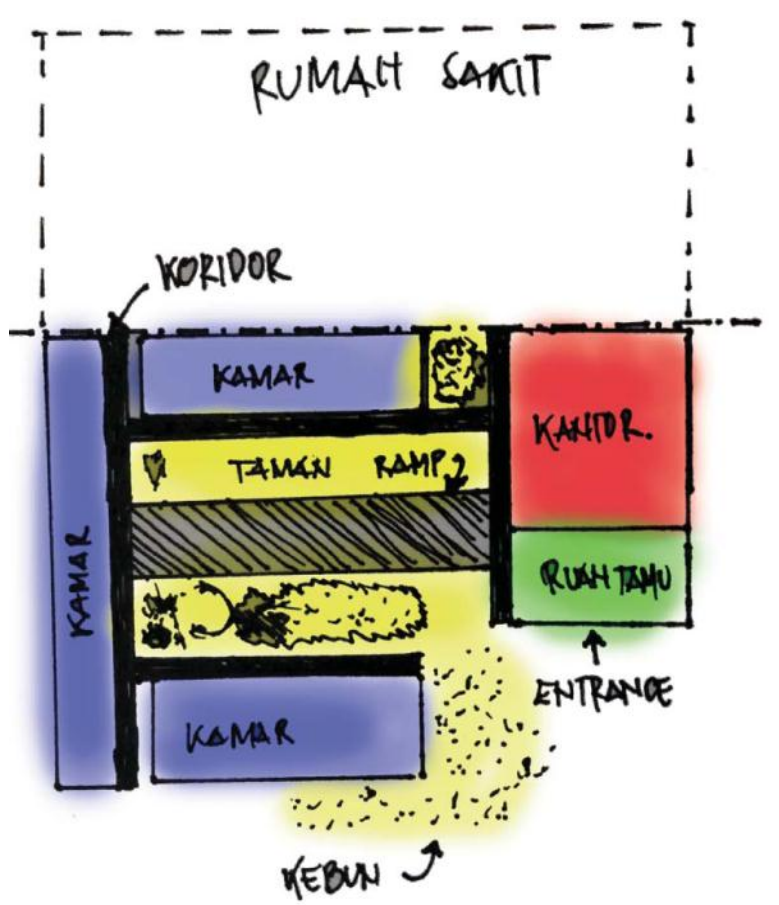

Figure 4. Sketch of room layout of Nursing Home of Santa Monika. 


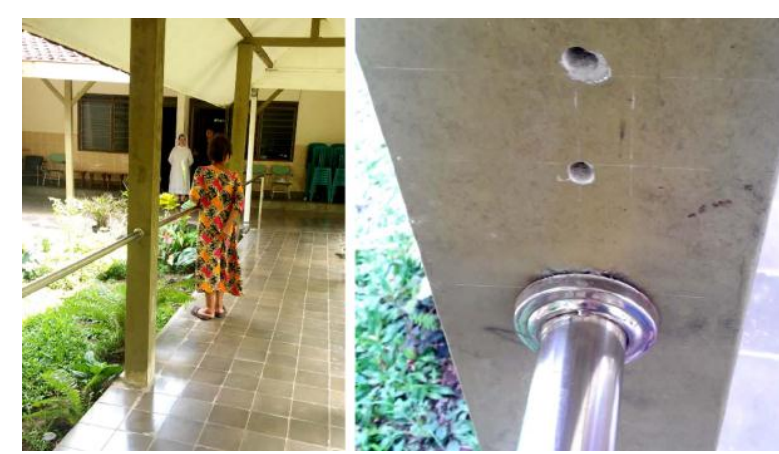

Figure 5. The elevation of handrail was lowered in order to accommodate physical changes of elderly.

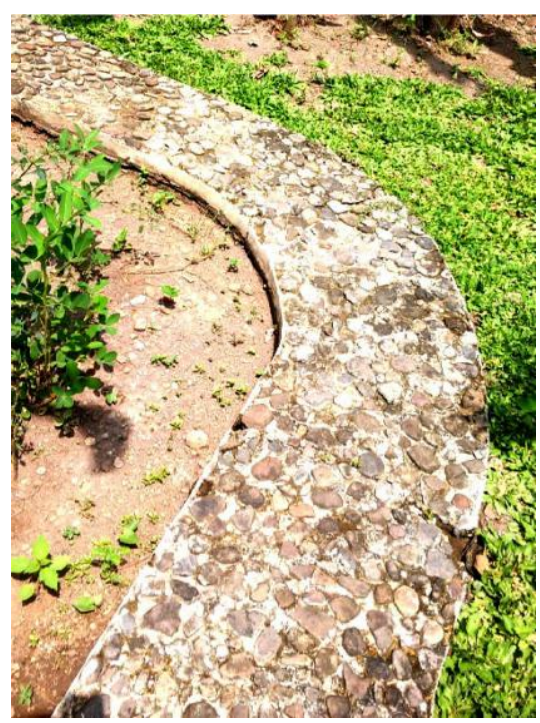

Figure 6. Circulation path as reflexology therapy

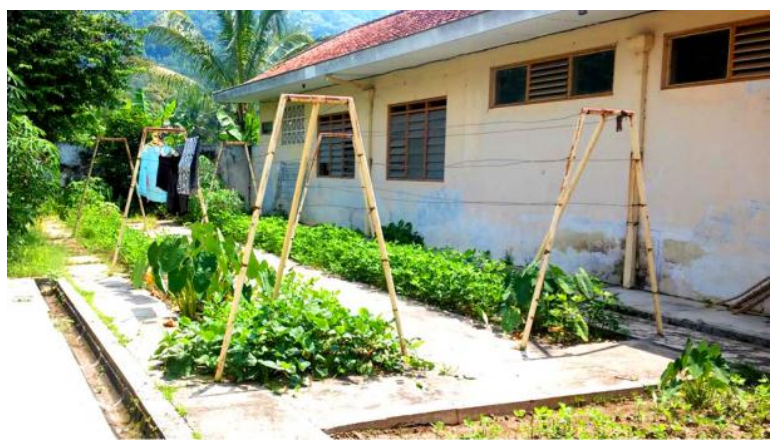

Figure 7. Gardening

Research was conducted at both locations showed how design changes and design development in the nursing home have been done in order to accommodate the needs of the elderly. The needs of the elderly occur due to changes in physical conditions, and their psychology. This also shows that the design should be done with user-oriented and does not use the standard in general. Different needs of the elderly with younger age because of a change in physical condition and ability to access and use space, as Calefato et al. (2014), that physical limitations caused by to age factor.

\section{CONCLUSION}

From the results of this study concluded that, needs of the elderly people in accessing and using the space has not been fulfilled. This happens not only in a nursing home that initially had different functions, but also in the building which originally was designed as a nursing home. Changes in physical conditions that occur in the elderly have not been accommodated in the design. Consequently, design developments made to meet the needs of the elderly.

Physical condition, behavior and activities of the elderly should be taken into consideration in the design of the nursing home, because of these three factors may affect the safety of the elderly. The design is oriented to the needs of the elderly can support the ability of elderly people to access and use space.

\section{ACKNOWLEDGMENT}

I would like to thank to all students participating in the course Inclusive Design who helped conduct field observations, measurements, interviews, as well as producing two-dimensional image, especially in the two study sites.

\section{REFERENCES}

(2013) Statistics Indonesia - Indonesia Population Projection 2010-2035

Benitez, J., Perejon, N., Arriaza, M., \& Bellanco, P. (2012). Nutritions study people over 80 years. European Journal of Investigation in Health, Psychology and Education, 2(3), p.77-89.

Belsy, J. (1999). "The Psychology of Aging: Theory, research, and interventions", Third Edition. Belmont: Wadsworth

Calefato, C. et al. (2014). Training Designers for Vulnerable Generations: A quest for a more inclusive design. Interaction Design and Architecture(s) Journal-IxD\&A, 21, p.25-36.

Chabeli, M.M. (2003). Health Care Needs of Older People Living Permanently in a Residential Home Setting in Gauteng. Curationis, 26(4), p.14-21.

Dzierzewski, J. et al. (2015). Self-reported sleep duration mitigates the association between inflammation and cognitive functioning in hospitalized older men. Journal of Frontries in Psychology, Vol.6, Article 1004. Accessed at http://journal. frontiersin.org/article/10.3389/fpsyg.2015.01004 /full. 
Liu, J.E. et al. (2015). Living Experience and Care Needs of Chinese Empty-nest Elderly People in Urban Communities in Beijing, China: A qualitative study. Nursing Sciences, 2, p.15-22.

Liu, Z., Beaver, K. \& Speed, S. (2014). Being healthy: A Grounded Theory study of Help Seeking Behaviour among Chinese Elders Living in the UK. Journal Qualitative Stud Health Well-being 2014, 9: 24820 http://dx.doi.org/10.3402/qhw.v9.24820.

Nurdiah, E.A., Asri, A. \& Hariyanto, A.D. (2015). Gendered Space in West Sumba Traditional Houses. Journal Dimensi, 42(2), p.69-75.

Nussbaumer, (2011), "Inclusive Design, A Universal Need, Fairchildbooks.
Ozcan, A., Donat, H., Gelecek, N., Ozdirenc, M. \& Karadibak, D. (2005). The Relationship between Risk Factors for Falling and the Quality of Life in Older Adults. BMC Public Health, 5: 9.

Ravishankar, V.K., Burleson, W. \& Mahoney. (2015). Smart home strategies for user-centered functional assessment of older adults. International Journal of Automation and Smart Technology, 5(4), p.233-242.

Steinfeld,E; \& Maisel,J.L, (2012), "Universal Design, Creating Inclusive Environments", John Willey $\&$ Sons, Inc. New Jersey.

Tanuwidjaja, G. (2014). Culture-Inclusive Toilet Design for YPAB Blind School in Surabaya. Journal Dimensi, 41(2), p.59-64. 